\title{
Avaliação da Implementação do "Projeto A Hora é Agora": Testagem e Tratamento do HIV/AIDS em Curitiba, Brasil
}

\author{
Marly Marques da Cruz, ${ }^{1}$ Vanda Lúcia Cota, ${ }^{2}$ \\ Carla Rocha Pereira, ${ }^{1}$ Adriana de Araújo Pinho ${ }^{3}$
}

RESUMO

Este trabalho tem por objetivo avaliar a implementação do "Projeto A Hora é Agora" (PAHA) que desenvolveu, em 2015, diferentes estratégias para ampliar a testagem e tratamento do HIV para os homens que fazem sexo com homens (HSH) residentes em Curitiba/PR. A análise partiu da perspectiva dos atores-chave envolvidos, utilizando uma abordagem qualitativa de investigação. A metodologia baseou-se em revisão documental, observações diretas, entrevistas semiestruturadas e discussão em grupos focais. Os resultados centraram-se em quatro subcategorias de acesso: cobertura; adequação; qualidade e aceitabilidade. A melhoria da cobertura foi vista no aumento de pontos de testagem, na ampliação dos dias e horários da testagem e retirada de antirretrovirais. Na adequação, os preceitos dos direitos humanos foram refletidos no respeito à privacidade e na agilidade na marcação de consultas/exames. A qualidade indicou as barreiras enfrentadas, como estigma e discriminação por parte de alguns profissionais de saúde. Por fim, a aceitabilidade revelou como cada estratégia foi aceita pelos HSH. Conclui-se que o PAHA foi uma intervenção bem-sucedida, ampliando a testagem e auxiliando os usuários a iniciarem o tratamento de HIV precocemente, incorporando novas tecnologias e abordagens no cuidado aos HSH.

Palavras-chave: avaliação em saúde; testes sorológicos; HIV; cuidado periódico; homossexualidade masculina.

IMPLEMENTATION ASSESSMENT OF “A HORA É AGORA" PROJECT:

TESTING AND HIV/AIDS TREATMENT IN CURITIBA, BRAZIL

\section{ABSTRACT}

This work aims evaluate the implementation of the "A Hora é Agora" Project (PAHA) was developed, in 2015, different strategies to expand HIV testing and treatment for men who have sex with men (MSM) living in Curitiba/PR. The analysis started from the perspective of the key actors involved, using a qualitative research approach. The methodology was based on document review, direct observations, semi-structural interviews and discussion in focus groups. The results focused on four access subcategories: coverage; adequacy; quality and acceptability. The improvement in coverage was seen in the increase of testing points, in the extension of the days and times of testing and withdrawal of antiretrovirals. In terms of adequacy, the precepts of human rights were reflected in respect for privacy and agility in making appointments/exams. The quality indicated the barriers faced, such as stigma and discrimination by some health professionals. Finally, acceptability revealed how each strategy was accepted by MSM. It is concluded that PAHA was a successful intervention, expanding testing and helping users to start HIV treatment, incorporating new technologies and approaches to MSM care.

Keywords: health evaluation; serologic tests; HIV; episode of care; male homosexuality.

RECEBIDO EM: 3/7/2020

MODIFICAÇÕES SOLICITADAS EM: 4/8/2020

ACEITO EM: 26/4/2021

\footnotetext{
${ }^{1}$ Escola Nacional de Saúde Pública Sérgio Arouca (Ensp/Fiocruz). Rio de Janeiro/RJ, Brasil.

2 Autora correspondente. Escola Nacional de Saúde Pública Sérgio Arouca (ENSP/Fiocruz). Rua Leopoldo Bulhões, 1.480, sala 6.010 - Bonsucesso. Rio de Janeiro/RJ, Brasil. CEP 21041-210. http://lattes.cnpq.br/6137119209692697. https://orcid. org/0000-0002-6823-9304. vanda.cota@ensp.fiocruz.br

${ }^{3}$ Instituto de Estudos em Saúde Coletiva (IESC/UFRJ). Cidade Universitária da Universidade Federal do Rio de Janeiro. Rio de Janeiro/RJ, Brasil.
} 


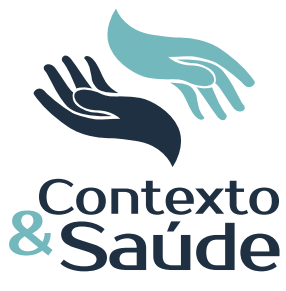

\section{INTRODUÇÃO}

No decorrer da epidemia de Aids, do começo da década de 80 do século 20 até os dias de hoje, acompanhamos o desenvolvimento de diversos avanços na prevenção, testagem e tratamento para as Pessoas Vivendo com HIV/Aids (PVHA), tanto no Brasil quanto no mundo (GRECO, 2016; MAEDA et al., 2019). O Brasil tem um papel de destaque, historicamente, na formulação de políticas de enfrentamento da epidemia e no uso de inovações tecnológicas (biomédicas e sociais) para o diagnóstico e tratamento das PVHA. Um dos pilares do programa do governo é a oferta universal de testes de HIV gratuitos, principalmente para promoção e ampliação de diagnóstico precoce e tratamento (MORA; BRIGEIRO; MONTEIRO, 2018).

Apesar da disponibilidade dos testes de HIV nas Unidades Básicas de Saúde (UBSs), dados divulgados em 2013 indicaram que apenas 36,1\% da população brasileira sexualmente ativa relatou já ter feito o teste (BRASIL, 2016).

Em populações específicas, como os homens que fazem sexo com homens (HSH), um estudo com amostragem realizada em 12 cidades do Brasil indicou um aumento significativo na infecção por HIV entre os HSH em comparação a um estudo anterior, de 12,1\% em 2009 para 18,4\% em 2016 (KERR et al., 2018). Segundo dados epidemiológicos brasileiros, os casos de infecção por HIV registrados no Sistema de Informação de Agravos de Notificação (Sinan) nos últimos 12 anos indicam que 52,3\% foram decorrentes de exposição homossexual e bissexual (BRASIL, 2019). Apesar da alta prevalência, a frequência de testagem do HIV entre HSH no Brasil é baixa, ocasionando o diagnóstico tardio (DE BONI et al., 2018).

Esses dados revelam a importância de se concentrar esforços na testagem de HIV entre os HSH, apontando para um potencial aumento na incidência do HIV nesta população e que envolvem ambientes de vulnerabilidade, estigma e discriminação para as populações-chave, como também mudanças de comportamento, políticas e programas (KERR et al., 2018).

Alguns passos foram dados nessa direção, como a realização de seminários entre o Departamento de IST/Aids e Hepatites Virais do Ministério da Saúde (MS) e Organizações Não Governamentais (ONGs) entre 2005 e 2007; desenvolvimento do "Plano Nacional de Enfrentamento da Epidemia de Aids e das DST entre Gays, HSH e Travestis", em 2007 (CALAZANS; PINHEIRO; AYRES, 2018), e iniciativas multilaterais, como o "Projeto Quero Fazer", em 2009, para garantir acesso ao serviço de testagem do HIV em cinco cidades brasileiras (MONTEIRO et al., 2019). Nesse escopo foi posto em prática o "Projeto A Hora é Agora" (PAHA), na cidade de Curitiba, Paraná, em 2014. Essa capital foi a escolhida em razão de alguns fatores, como: descentralização do diagnóstico do HIV para a atenção básica desde 2002, ampliando a realização do exame nas UBSs da rede municipal; no mesmo ano começou a notificar todos os casos de HIV, tornando-se uma prática pelo MS somente em 2014, e ser signatária da Declaração de Paris, comprometendo-se a acelerar a resposta para o fim da Aids. Esse projeto foi elaborado a partir de protocolos de pesquisa e desenvolvido por meio de uma parceria entre a Escola Nacional de Saúde Pública Sergio Arouca (ENSP/Fiocruz), o Departamen-

Editora Unijuí - Revista Contexto \& Saúde - ISSN 2176-7114 - v. 21, n. 43, jul./set. 2021 


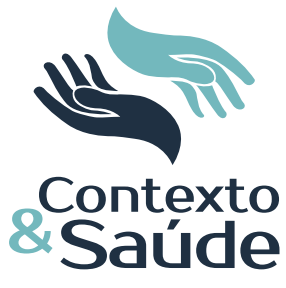

to de Doenças de Condições Crônicas e Infecções Sexualmente Transmissíveis do Ministério da Saúde, a Secretaria Municipal de Saúde (SMS) de Curitiba, o Grupo Dignidade (ONG que trabalha com a população LGBTI+ de Curitiba) e os Centros de Controle e Prevenção de Doenças dos Estados Unidos (CDC).

O PAHA contou com diferentes tipos de estratégias para ampliar a testagem rápida de HIV, seguindo a premissa de fornecer locais de fácil acesso e horários alternativos, tais como o Grupo Dignidade (ONG), o Centro de Orientação e Aconselhamento (COA), o Consultório na Rua (CR) e a unidade móvel (trailer). Também foi ofertado, especialmente para os jovens HSH, uma plataforma on-line (https://www.ahoraeagora.org/) com o objetivo de fornecer informações sobre a prevenção do HIV, um instrumento para o usuário realizar uma autoavaliação de risco, além da possibilidade de os usuários com 18 anos ou mais, moradores de Curitiba, solicitarem por esta plataforma kits de testes rápidos de fluido oral para autotestagem (E-testing) (DE BONI et al., 2018). O E-testing foi uma das estratégias do projeto, por meio da qual os HSH poderiam receber os testes em casa (pelo Correio) ou retirar na farmácia popular.

Outra estratégia utilizada do PAHA foi a "navegação" por pares (SHACHAM et al., 2018), também chamada de "linkagem" (LABHARDT et al., 2018). Nela, um "linkador", normalmente HSH treinado, era designado para auxiliar e acompanhar cada HSH com teste reagente de HIV por até três meses (90 dias) nas UBSs vinculadas ao Sistema Único de Saúde (SUS), desde o momento da marcação de consultas médicas/exames até a sua aderência à terapia antirretroviral (Tarv). 0 projeto também se propôs, em seu protocolo, a fornecer espaços livres de estigma e discriminação para garantir um lugar acolhedor para os HSH, incentivando e facilitando a testagem de HIV para o grupo.

O PAHA foi um projeto de ciência de implementação, desenvolvido durante um período de dois anos e meio e, após 14 meses, foi iniciada a avaliação do processo de implementação do programa no intuito de saber o quanto as estratégias garantiam o acesso e eram aceitas pela população HSH, se eram sustentáveis e replicáveis em outros contextos. Esta pesquisa avaliativa visou à aplicação sistemática de diversos procedimentos para aprofundar a análise da intervenção, por meio de bases teóricas e/ou processos operacionais nos contextos existentes, levando-se em consideração a visão dos distintos atores envolvidos (SALCl; SILVA; MEIRELLES, 2018).

A avaliação do PAHA foi composta por quatro objetivos: 1) explicar as variáveis-chave de implementação do programa - relevância e pertinência, aceitabilidade, adoção, viabilidade, fidelidade, penetração e sustentabilidade dos serviços e atividades; 2) avaliar a efetividade das diferentes estratégias para o alcance das metas do programa; 3 ) identificar as principais barreiras e os fatores facilitadores para implementação e 4) identificar e compartilhar as principais lições aprendidas. O presente artigo, no entanto, tem por objetivo avaliar a implementação do PAHA a partir da perspectiva dos atores-chave envolvidos neste processo, utilizando uma abordagem qualitativa de investigação/análise e com base: a) em quatro variáveis-chave de implementação selecionadas para o artigo; b) na identificação das principais barreiras e facilitadores das variáveis-chave analisadas.

Editora Unijuí - Revista Contexto \& Saúde - ISSN 2176-7114 - v. 21, n. 43, jul./set. 2021 


\section{MATERIAIS E MÉTODOS}

A pesquisa qualitativa tem se consolidado no campo da saúde coletiva desde a década de 90, quando estudos referentes à sexualidade, Aids, corporalidade, exclusão social e vulnerabilidade começaram a ser desenvolvidos (KNAUTH; LEAL, 2014). Essas pesquisas empregam metodologias das chamadas Ciências Sociais, como pesquisa documental, entrevistas em profundidade (também chamadas de semiestruturais), observação direta, grupos focais, entre outros. Já a pesquisa avaliativa qualitativa busca avaliar um programa, projeto ou mesmo uma proposta política, seja pública ou institucional, a partir das representações, percepções, emoções e observação das relações e práticas envoltas na introdução e/ou desenvolvimento da ação (MINAYO, 2011).

A pesquisa avaliativa ocorreu durante os meses de setembro a dezembro de 2016. Uma equipe externa de avaliação composta por uma consultora independente e três pesquisadoras-entrevistadoras foram responsáveis pela coleta e análise dos dados qualitativos. Distintas técnicas foram utilizadas para a melhor apreensão do objeto de investigação em questão: a) revisão documental (memórias das reuniões do Comitê Gestor, relatórios de supervisão, oficina de harmonização e documentos que foram publicados no período pré-instalação do projeto, como normas, portarias, inquéritos, etc.); b) observações diretas das estruturas e atividades nos serviços de Aconselhamento e Testagem Voluntária (ATV) do PAHA (COA, CR, ONG e trailer - destacando-se que cada estratégia foi observada três vezes); c) entrevistas semiestruturadas com informantes-chave (EIC) e d) discussão em grupos focais (DGF) com os prestadores de serviços do projeto e HSH, sendo estes usuários ou não dos serviços ofertados pelo PAHA.

Foram desenvolvidos roteiros para a realização das observações diretas, entrevistas e grupos focais, ressaltando-se que para os dois últimos ainda foram utilizadas fichas sociodemográficas para descrever o perfil dos participantes. Eles foram selecionados por conveniência visando ao objetivo de entrevistar casos ricos de informação sobre o estabelecimento do PAHA (PATTON, 2015). Os roteiros para as entrevistas e grupos focais abarcaram diversas questões do projeto, como a qualidade da intervenção, os resultados não intencionais positivos e negativos, as barreiras e os facilitadores para o desenvolvimento do PAHA, entre outros.

No que diz respeito à captação de HSH para participarem da avaliação, os gays/HSH (usuários e não usuários do PAHA) foram convidados por meio de comunicação nas redes sociais (Fanpage no Facebook e Instagram), de parceiros (Revista Lado A); por contato pessoal; divulgação em salas de bate-papo do site UOL (consideradas salas de namoro ou "pegação" para o público gay/bissexual); material de divulgação (flyers e cartazes); disponibilização de telefone e e-mail e ainda a produção de um vídeo com um educador de pares disponibilizado no site do PAHA. Grande parte dos HSH participantes das entrevistas e grupos focais, contudo, foi oriunda da própria rede da equipe do projeto. Os prestadores de serviços foram selecionados por meio de indicações das equipes dos serviços; os demais participantes, por exemplo, membros da sociedade civil, autoridades go-

Editora Unijuí - Revista Contexto \& Saúde - ISSN 2176-7114 - v. 21, n. 43, jul./set. 2021 
vernamentais, coordenadores locais dos serviços, aconselhadores, linkadores e educadores foram recrutados diretamente pela equipe do estudo.

Ao todo, foram realizadas 18 entrevistas semiestruturadas com informantes-chave, 14 entrevistas com gays/HSH residentes em Curitiba, 4 grupos focais e 12 dias de observação nas estratégias, 3 deles para cada estratégia (COA, CR, ONG e trailer), nos horários de atendimento de cada estratégia, utilizando o método etnográfico para investigar as estruturas e atividades de atendimentos dos serviços prestados pelo PAHA. Entre os participantes havia gestores, profissionais de saúde, ativistas e HSH. Cinquenta pessoas participaram da fase qualitativa da avaliação do projeto, entre entrevistas individuais e grupos focais, como descrito no Quadro 1. O perfil dos usuários do PAHA era de jovens, somente seis eram maiores de 29 anos, todos se autodeclararam gays/bissexuais e possuíam Ensino Médio e Superior completo, com exceção de um entrevistado com Ensino Médio incompleto.

As entrevistas com os informantes-chave foram realizadas em uma sala privativa, com duração média de 60 minutos, gravadas em áudio e posteriormente transcritas. Algumas entrevistas, contudo, foram conduzidas virtualmente, por Skype, para aqueles que não residiam/trabalhavam na mesma cidade das entrevistadoras. Os grupos focais foram realizados com, no mínimo, quatro participantes e, no máximo, dez, com a gravação de áudios que após foram transcritos. Eles foram realizados em uma sala privativa ou em outro local adequado/acessível e conhecido pelos participantes, com uma duração média de duas horas.

Quadro 1 - Número total e perfil de entrevistas e grupos focais da avaliação do PAHA. Projeto AHA, Curitiba, 2015-2017

\begin{tabular}{|l|c|c|c|}
\multicolumn{1}{|c|}{ Informantes-chave } & \multicolumn{2}{c|}{ Técnica } & \multicolumn{1}{|c|}{$\begin{array}{c}\text { Total de } \\
\text { participantes }\end{array}$} \\
\cline { 2 - 4 } & EIC* & DGF* & \\
\hline $\begin{array}{l}\text { Gestores e implementadores (vigilância, direitos } \\
\text { humanos e pontos focais) }\end{array}$ & 10 & 0 & 10 \\
\hline $\begin{array}{l}\text { Profissionais de saúde prestadores de serviços do } \\
\text { PAHA }\end{array}$ & 3 & 3 & 18 \\
\hline $\begin{array}{l}\text { Profissionais de saúde não prestadores diretos de } \\
\text { serviços do PAHA }\end{array}$ & 3 & 0 & 3 \\
\hline $\begin{array}{l}\text { Integrantes de ONG (dirigentes e ativistas voluntários) } \\
\text { HSH/Gays usuários das estratégias de ATV }\end{array}$ & 2 & 0 & 2 \\
\hline HSH/Gays não usuários (nunca fizeram o teste) & 6 & 1 & 9 \\
\hline Total & $\mathbf{3 2}$ & $\mathbf{4}$ & $\mathbf{5 0}$ \\
\hline
\end{tabular}

* Entrevistas com Informantes-chave.

** Discussão em grupos focais (com distintos números de participantes em cada grupo).

Fonte: Elaborado pelos autores, 2020.

Para atender aos objetivos de avaliação do PAHA foram criadas sete questões-chave (KEQs), com suas respectivas subquestões, e analisadas conjuntamente com as variáveis de implementação (PROCTOR et al., 2011). Além disso, outros componentes foram incluídos, como o nível ou unidade de análise, se por tipo de estratégia (diferentes serviços e vinculação) ou recipientes (executores, prestadores de serviços e beneficiários/usuários), como também o método de coleta utiliza- 
do para responder a cada questão, descritos no Quadro 2. A triangulação dos dados coletados foi realizada a partir de procedimentos narrativos e de análise temática, permitindo avaliar o contexto social como um todo em razão da experiência vivida por todos os participantes, além de identificar temas e tópicos específicos relacionados às questões-chave de avaliação. Foram elaboradas planilhas-resumo para produzir coletivamente um esquema de codificação temática relacionado às questões-chave. Com base nas planilhas-resumo foram criadas manualmente matrizes temáticas em Microsoft Excel de modo a facilitar as comparações entre categorias e participantes das entrevistas. Uma leitura transversal das matrizes foi, então, conduzida a fim de identificar as categorias de análise e os pontos de convergência e divergência entre as diferentes narrativas, agregando, a partir desta análise, informações pertinentes para responder às questões-chave de avaliação, juntamente com o material proveniente das observações e revisão documental.

Quadro 2 - Questões e variáveis-chave de avaliação, unidade de análise e método de coleta, Projeto AHA, Curitiba, 2015-2017

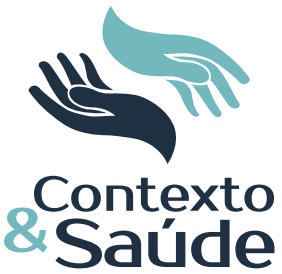

\begin{tabular}{|c|c|c|c|c|}
\hline $\begin{array}{l}\text { Questão-chave } \\
\text { de avaliação }\end{array}$ & Subquestões & $\begin{array}{l}\text { Variáveis-chave de } \\
\text { implementação }\end{array}$ & $\begin{array}{l}\text { Nível/unida- } \\
\text { de de análise }\end{array}$ & Método de coleta \\
\hline $\begin{array}{l}\text { KEQ1. Qual é } \\
\text { a relevância, } \\
\text { adequação e } \\
\text { qualidade da } \\
\text { estrutura da } \\
\text { intervenção? }\end{array}$ & $\begin{array}{l}\text { a) A intervenção é condi- } \\
\text { zente com os compro- } \\
\text { missos e plano estratégi- } \\
\text { co do país para suprir as } \\
\text { necessidades dos HSH } \\
\text { relativas ao HIV? } \\
\text { b) A estrutura da interven- } \\
\text { ção é sólida do ponto de } \\
\text { vista técnico? } \\
\text { c) A estrutura da inter- } \\
\text { venção favorece os } \\
\text { preceitos de direitos } \\
\text { humanos? }\end{array}$ & $\begin{array}{l}\text { - Relevância } \\
\text { - Adequação/per- } \\
\text { tinência } \\
\text { - Qualidade }\end{array}$ & $\begin{array}{l}\text { Por tipo de } \\
\text { beneficiário e } \\
\text { por estratégia }\end{array}$ & $\begin{array}{l}\text { - Revisão docu- } \\
\text { mental } \\
\text { - Entrevistas se- } \\
\text { miestruturadas } \\
\text { - Grupos focais } \\
\text { - Observação dire- } \\
\text { ta da prestação } \\
\text { de serviços }\end{array}$ \\
\hline $\begin{array}{l}\text { KEQ2. Qual é o } \\
\text { nível de institui- } \\
\text { ção e adaptação } \\
\text { da intervenção } \\
\text { conforme a } \\
\text { necessidade? }\end{array}$ & $\begin{array}{l}\text { a) Qual é o nível de eficácia } \\
\text { dos sistemas internos } \\
\text { para o controle do anda- } \\
\text { mento em relação aos } \\
\text { planos e para a modifi- } \\
\text { cação da efetivação con- } \\
\text { forme a necessidade? } \\
\text { b) A intervenção foi ajus- } \\
\text { tada durante o período } \\
\text { de introdução a fim de } \\
\text { alinhá-la a novas neces- } \\
\text { sidades e evidências? }\end{array}$ & $\begin{array}{l}\text { - Fidelidade } \\
\text { - Adoção } \\
\text { - Penetração }\end{array}$ & $\begin{array}{l}\text { Por tipo de } \\
\text { beneficiário e } \\
\text { por estratégia }\end{array}$ & $\begin{array}{l}\text { - Entrevistas se- } \\
\text { miestruturadas } \\
\text { - Grupos focais } \\
\text { - Observação de } \\
\text { campo } \\
\text { - Visitas de } \\
\text { supervisão } \\
\text { - Observação di- } \\
\text { reta } \\
\text { da prestação de } \\
\text { serviços }\end{array}$ \\
\hline $\begin{array}{l}\text { KEQ3. A inter- } \\
\text { venção produziu } \\
\text { os resultados } \\
\text { pretendidos no } \\
\text { curto, médio e } \\
\text { longo prazo? }\end{array}$ & $\begin{array}{l}\text { Os resultados pretendidos } \\
\text { foram alcançados? O que } \\
\text { deu certo para quem, em } \\
\text { que medida e de que ma- } \\
\text { neiras? }\end{array}$ & $\begin{array}{l}\text { - Efetividade } \\
\text { - Cobertura }\end{array}$ & $\begin{array}{l}\text { Por tipo de } \\
\text { beneficiário e } \\
\text { por estratégia }\end{array}$ & $\begin{array}{l}\text { - Indicadores pro- } \\
\text { gramáticos } \\
\text { - Entrevistas se- } \\
\text { miestruturadas } \\
\text { - Grupos focais }\end{array}$ \\
\hline
\end{tabular}




\begin{tabular}{|c|c|c|c|c|}
\hline $\begin{array}{l}\text { KEQ4. Que } \\
\text { resultados não } \\
\text { intencionais (po- } \\
\text { sitivos e negati- } \\
\text { vos) a interven- } \\
\text { ção produziu? }\end{array}$ & $\begin{array}{l}\text { Houve alguma mudança } \\
\text { não intencional na vida dos } \\
\text { usuários da intervenção, no } \\
\text { ambiente de prestação de } \\
\text { serviços e na comunidade } \\
\text { em geral? }\end{array}$ & $\begin{array}{l}\text { - Viabilidade } \\
\text { - Aceitabilidade }\end{array}$ & $\begin{array}{l}\text { Por tipo de } \\
\text { beneficiário e } \\
\text { por estratégia }\end{array}$ & $\begin{array}{l}\text { - Entrevistas se- } \\
\text { miestruturadas } \\
\text { - Grupos focais } \\
\text { - Visitas de super- } \\
\text { visão } \\
\text { - Revisão de atas } \\
\text { de reunião do co- } \\
\text { mitê gestor } \\
\text { - Pesquisa de saída } \\
\text { com usuários HSH }\end{array}$ \\
\hline $\begin{array}{l}\text { KEQ5. Quais fo- } \\
\text { ram as barreiras } \\
\text { e facilitadores } \\
\text { que fizeram a } \\
\text { diferença entre } \\
\text { o sucesso e o } \\
\text { fracasso da efe- } \\
\text { tivação e resul- } \\
\text { tados da inter- } \\
\text { venção? Quais } \\
\text { são as lições } \\
\text { aprendidas? }\end{array}$ & $\begin{array}{l}\text { a) Quais foram os gargalos } \\
\text { que impediram o suces- } \\
\text { so de algum componen- } \\
\text { te da intervenção e se } \\
\text { houve formas eficazes de } \\
\text { superá-los? } \\
\text { b) Quais foram os facilitado- } \\
\text { res da introdução e se há } \\
\text { condições específicas em } \\
\text { que eles foram/podem } \\
\text { ser maximizados? } \\
\text { c) Quais foram os fracassos } \\
\text { ou processos que não } \\
\text { funcionaram ou não se } \\
\text { mostraram eficazes na } \\
\text { instauração? }\end{array}$ & $\begin{array}{l}\text { - Adoção } \\
\text { - Penetração } \\
\text { - Viabilidade }\end{array}$ & $\begin{array}{l}\text { Por tipo de } \\
\text { beneficiário e } \\
\text { por estratégia }\end{array}$ & $\begin{array}{l}\text { - Entrevistas se- } \\
\text { miestruturadas } \\
\text { - Grupos focais } \\
\text { - Visitas de super- } \\
\text { visão } \\
\text { - Revisão de atas } \\
\text { de reunião do co- } \\
\text { mitê gestor }\end{array}$ \\
\hline $\begin{array}{l}\text { KEQ6. Qual foi } \\
\text { o valor dos re- } \\
\text { sultados para os } \\
\text { participantes, } \\
\text { prestadores } \\
\text { de serviços, } \\
\text { organizações } \\
\text { envolvidas e a } \\
\text { comunidade em } \\
\text { geral? }\end{array}$ & $\begin{array}{l}\text { a) Em que medida as con- } \\
\text { quistas foram valorizadas } \\
\text { pelas diversas partes } \\
\text { interessadas do progra- } \\
\text { ma e pela comunidade } \\
\text { em geral? } \\
\text { b) Houve consensos/diver- } \\
\text { gências fundamentais } \\
\text { naquilo que foi valori- } \\
\text { zado, por quem? Quais } \\
\text { foram os motivos? }\end{array}$ & $\begin{array}{l}\text { - Aceitabilidade } \\
\text { - Adoção }\end{array}$ & $\begin{array}{l}\text { Por tipo de } \\
\text { beneficiário e } \\
\text { por estratégia }\end{array}$ & $\begin{array}{l}\text { - Entrevistas se- } \\
\text { miestruturadas } \\
\text { - Grupos focais } \\
\text { - Visitas de super- } \\
\text { visão } \\
\text { - Revisão atas de } \\
\text { reunião do comi- } \\
\text { tê gestor }\end{array}$ \\
\hline $\begin{array}{l}\text { KEQ7. Os resul- } \\
\text { tados positivos } \\
\text { têm chances de } \\
\text { serem manti- } \\
\text { dos? }\end{array}$ & $\begin{array}{l}\text { a) Os resultados foram obti- } \\
\text { dos de forma sustentável? } \\
\text { b) Em que medida foram } \\
\text { criadas e institucionalizadas } \\
\text { apropriação e capacidades } \\
\text { locais? } \\
\text { c) Em que medida recursos } \\
\text { locais estão disponíveis } \\
\text { para manter as atividade e } \\
\text { resultados? } \\
\text { d) Alguma área da interven- } \\
\text { ção é claramente insusten- } \\
\text { tável? }\end{array}$ & - Sustentabilidade & $\begin{array}{l}\text { Por tipo de } \\
\text { beneficiário e } \\
\text { por estratégia }\end{array}$ & $\begin{array}{l}\text { - Entrevistas se- } \\
\text { miestruturadas } \\
\text { - Grupos focais } \\
\text { - Visitas de super- } \\
\text { visão } \\
\text { - Revisão atas de } \\
\text { reunião do comi- } \\
\text { tê gestor }\end{array}$ \\
\hline
\end{tabular}

Fonte: Elaborado pelos autores, 2020. 


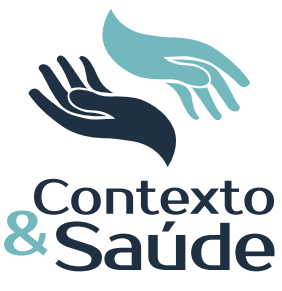

Para este artigo, a estratégia de análise da avaliação foi centrada em quatro categorias que englobam as dimensões de acesso ao PAHA: cobertura; adequação; qualidade e aceitabilidade. Essas categorias fazem parte das variáveis-chave de implementação do PAHA, descritas no Quadro 2, sendo aquelas que se destacaram para entender o acesso dos usuários aos serviços na testagem e tratamento de HIV/Aids em Curitiba. Os temas discutidos, tanto nas entrevistas quanto nos grupos focais, tiveram como base perguntas para responder às sete questões-chave de avaliação.

Para cada categoria analisada foi desenvolvida uma descrição com base na reflexão conceitual de alguns autores, como também a partir de pesquisas empíricas, tais como: a) Cobertura vinculada à amplitude e aos tipos de serviços ofertados aos usuários, além da experiência e informações sobre eles, podendo influenciar na demanda dos serviços; primordialmente na testagem de HIV para saber se o público-alvo está conseguindo realizá-la em um dos locais do PAHA (MATIN et al., 2019); b) Adequação relacionada à organização dos recursos da testagem no PAHA, se atende ou não a todas as necessidades dos usuários do serviço, além de entender a experiência deles com a organização do serviço de testagem (PENCHANSKY; THOMAS, 1981; VIACAVA et al., 2012); c) Qualidade, correspondente à qualidade da atenção/cuidado que está sendo ofertada no serviço e a percepção de efetividade para ampliar o acesso, a capacitação profissional das equipes, a percepção da satisfação dos usuários, além de fatores individuais dos profissionais de saúde. Essa categoria informa se os direitos e dignidade dos usuários foram respeitados nos atendimentos, como também o cuidado prestado, a conformação das instalações (estrutura física) e os fatores contextuais (EMMERICK et al., 2015); d) Aceitabilidade, refere-se à avaliação das atitudes dos usuários diante da aceitação do tipo de testagem disponibilizado no PAHA, ou seja, se o atendimento está dentro das expectativas dos HSH (VIACAVA et al., 2012).

Apesar de a categoria sustentabilidade ser considerada central para a manutenção da estratégia em Curitiba, fazendo parte das questões-chave, ela não será aprofundada neste artigo. A análise dos dados teve como base a literatura em torno do campo da avaliação em saúde, sobretudo para a seleção das categorias discutidas ao longo do artigo e centrais nesse tipo de trabalho.

O projeto de pesquisa foi submetido ao Comitê de Ética em Pesquisa da Escola Nacional de Saúde Pública Sergio Arouca/Fiocruz, à Comissão Nacional de Ética em Pesquisa (Conep), e ao Comitê de Ética da Secretaria Municipal de Saúde de Curitiba - PR em 2016, tendo os pareceres n. 1.472.573, 1.707.476 e 125/2016, respectivamente. Os Termos de Consentimento Livre e Esclarecido (TCLEs) foram aplicados e obtidos de todos os participantes da pesquisa, após explicação dos propósitos, metodologia, riscos e benefícios relacionados à participação.

\section{RESULTADOS}

\section{Cobertura}

A ampliação do acesso à testagem para o público-alvo a partir de distintas abordagens e opções foi enfatizada como fator positivo entre os profissionais participantes do PAHA, que destacaram a oferta de vários pontos de testagem, o

Editora Unijuí - Revista Contexto \& Saúde - ISSN 2176-7114 - v. 21, n. 43, jul./set. 2021 


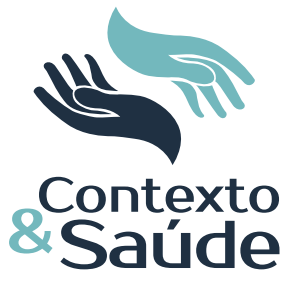

aumento de dias e horários nas estratégias (horário noturno e sábados, como no trailer) e a vinculação precoce (acelerando o início do tratamento de HIV/Aids). Igualmente, a ampliação de locais e horários para a retirada dos antirretrovirais (ARV) foi uma questão reiterada pelos entrevistados, considerada fundamental para a melhoria do acesso ao tratamento:

Outra coisa também que eu acho legal que o projeto fez assim, é dar uma autonomia pro usuário, entendeu? Porque você pode ir na ONG, você pode ir no trailer, você pode ir no COA e você pode fazer o teste em casa... isso é legal porque assim, muitas pessoas não se testavam por conta de não querer ir no serviço, entendeu? Pela questão da exposição [...] (educador de pares 2).

Para a população em situação de rua, houve a ampliação da testagem e que conferiu certo acesso desses indivíduos às estruturas formais de cuidado à saúde por meio do PAHA. Isso também possibilitou o acesso ao diagnóstico precoce de HIV para uma parte da população socialmente excluída, com base nas diretrizes do SUS e que embasavam as ações do Consultório na Rua do Município.

A despeito da ampliação da testagem para o HIV em Curitiba apontada pelos entrevistados, houve uma falta de conhecimento entre os HSH sobre os serviços de testagem nas UBSs, mesmo após a descentralização da atenção ao HIV/Aids, exigindo assim maior divulgação da testagem rápida. Para aqueles que sabiam da possibilidade do teste rápido, ele foi preferencialmente realizado em serviços especializados, como o COA, mesmo que o acesso a este para testagem representasse exposição à preferência sexual dos usuários e a potencial associação com a soropositividade, como indica um entrevistado: “Então, eu já passei ali próximo com amigos e não sei, as pessoas, eu vejo preconceito também nas pessoas, elas sempre falam quando alguém sai do prédio, aí está saindo do COA" (homem gay, usuário E-testing, soropositivo, 33 anos).

\section{Adequação}

A estruturação do PAHA e a organização de suas atividades deu-se a partir da incorporação dos preceitos dos direitos humanos no processo de trabalho das equipes, sendo visto como uma alternativa de testagem mais acolhedora e com um atendimento rápido, eficiente e de qualidade na oferta da testagem e tratamento. Nas entrevistas isso refletiu-se em relatos sobre a humanização na atenção das necessidades dos HSH, no respeito à privacidade (entre os profissionais e os usuários do serviço), na ampliação de locais e horários de atendimento, na maior agilidade de marcação de consultas e exames (por meio do papel do linkador), na comunicação dos educadores de pares (jovens gays) e na divulgação do projeto para diferentes perfis de HSH. Em algumas estratégias o sigilo foi incorporado na estrutura e na organização do espaço de atendimento, como na existência de uma "porta de fundos" na saída do trailer, permitindo discrição, no reforço do isolamento acústico na ONG, entre outras iniciativas:

[...] a estrutura que o projeto nos forneceu, por exemplo, no caso o equipamento no trailer, ele trouxe assim mais um local de alternativa para a população-chave procurar, um local onde não tem estigma, não tem preconceito e eles se sentem mais à vontade (ponto focal 2).

Editora Unijuí - Revista Contexto \& Saúde - ISSN 2176-7114 - v. 21, n. 43, jul./set. 2021 


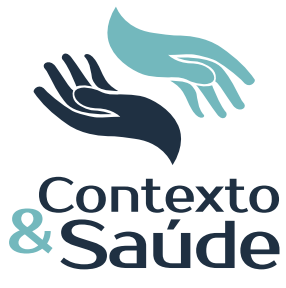

Para alguns gestores e outros profissionais, a figura do linkador foi primordial. Ele atuou como um agente-mediador com a UBS, tentando mitigar os efeitos das barreiras de acesso aos serviços de saúde e sinalizando a existência/persistência delas para as unidades e à SMS. Segundo os informantes-chave, houve dificuldades dos usuários LGBTQI+ na rede pública de assistência relacionadas, por exemplo, à persistência do estigma e da discriminação no atendimento. Embora a estrutura e a organização do PAHA tenha visado à ampliação da capacidade local para a prestação de testagem e vinculação ao tratamento do HIV de qualidade para a população HSH, as capacitações realizadas para profissionais de saúde (direitos LGBTQI+, estigma e discriminação) restringiram-se às equipes do PAHA, não se estendendo à rede básica de saúde e refletindo no atendimento prestado.

No que se refere ao direito ao acesso do segmento mais vulnerável socialmente, como a população de rua, a organização desse tipo de assistência foi pensada para garantir o acesso aos usuários marginalizados, principalmente àqueles sem documentação, a partir de estratégicas intersetoriais com a assistência social, como referido por um dos informantes

[...] a gente tem trabalhado maciçamente junto com a assistência social no sentido da confecção dos documentos deles, pra que não haja, então, um prejuízo ou um atraso no início do tratamento (ponto focal 4).

Como forma de aperfeiçoar a adequação das estratégias de testagem do PAHA, foram providenciados, junto as equipes, os Procedimentos Operacionais-Padrão (POP), que foram colocados de forma visível em todas as estratégias, e ajustes em relação aos fluxos e processos de trabalho. Nas observações diretas realizadas nas estratégias, percebeu-se que as equipes da ONG e do trailer seguiam os fluxos dos atendimentos e os espaços eram limpos e acolhedores. A ONG tinha um lugar mais "gay-friendly" (cartazes voltados para esse público e divulgação de ações de cidadania) e o trailer contava mais com a presença de profissionais com identidade LGBTQI+.

A estratégia com maior dificuldade de adequação à estrutura e à qualidade da atenção à população LGBTQI+ foi o COA. Lá foi observada a falta de padronização do fluxo dos usuários e procedimentos entre os profissionais do serviço, além do pouco conhecimento da equipe sobre o projeto. A explicação para os usuários sobre o PAHA era delegada, muitas vezes, aos linkadores. Houve também pouca interação entre os profissionais do COA e a equipe do PAHA; ocorreu relato de atendimentos dos usuários sem discrição e privacidade; houve a identificação de falas de aconselhadores com teor estigmatizante e repasse de informações técnicas com erros (discurso centrado no pânico e moralismo), entre outros problemas.

\section{Qualidade}

Para os usuários do PAHA, de modo geral, a atenção em saúde ofertada pelos serviços do programa foi realizada por profissionais qualificados tecnicamente e humanizados, sem práticas discriminatórias em relação às identidades de gênero, sexualidade e ao HIV. Por outro lado, isso aparece nas barreiras en-

Editora Unijuí - Revista Contexto \& Saúde - ISSN 2176-7114 - v. 21, n. 43, jul./set. 2021 
frentadas pelos HSH no sistema de saúde local, presente no registro dos linkadores, referidos ao estigma e discriminação sofridos e também na organização dos serviços, como demora na marcação de consultas e realização de exames; tempo de espera para o atendimento; falta de profissionais nos serviços de saúde; desconhecimento de novas tecnologias de prevenção e tratamento, além da dificuldade em lidar com questões de sexualidade para o cuidado da saúde dessa população. Outros fatores também foram ponderados e relacionados à qualidade, como segurança, confidencialidade e sigilo, importantes na garantia do acesso aos serviços para determinadas populações como os HSH, que não se identificam como gays ou homossexuais:

Bastante preconceito, eu acho que a principal barreira é essa [...] alguns não querem se expor e têm que se expor, e os que não se importam de serem assumidos [como soropositivos] [...] sofrem um preconceito muito grande também. Então, o que eu vejo é isso, barreira é o preconceito (homem gay, usuário E-testing, 21 anos).

De acordo com alguns informantes-chave da pesquisa, um melhor acoIhimento estaria dentro do modelo de cuidado integral para as PVHA, com discursos menos tecnicistas e não estigmatizantes e o cuidado integral e integrado desses sujeitos a outros serviços, numa perspectiva multidisciplinar. Para isso, além da capacitação das equipes, o processo de trabalho deveria ser baseado na humanização, na integridade e nos direitos das PVHA. Sigilo e discrição também fariam parte desse acolhimento, pois a forma como era realizada a retirada dos medicamentos nas unidades dispensadoras contribuiu para o processo de estigmatização dos HSH. Mesmo nos lugares considerados bons para a testagem, como o COA, a estrutura física não foi pensada para mitigar o estigma ou para garantir a manutenção do sigilo durante o tratamento, como relatam os entrevistados:

[...] às vezes, você pega um atestado e está escrito COA lá embaixo, eu não posso entregar lá porque se eu entregar o meu chefe vai falar, mas por que treze atestados do COA? A minha médica inclusive tira aquela parte pra mim, que eu solicito pra ela, pra não ficar escrito ali né, COA. Então, eu acho que o COA é importante, porque eles são muito preparados, mas ao mesmo tempo não é tão discreto (homem gay, usuário do PAHA, soropositivo, 35 anos).

[...] lá tem uma sala de espera e aí começa a chamar nomes, chamar pessoas [...] a maior parte que estava lá pra pegar medicação sabia que eu [...] quase todo mundo que estava lá estava pegando medicação de HIV (homem gay, usuário do PAHA, 35 anos).

No que diz respeito à estrutura física dos locais de testagem do PAHA, os entrevistados sentiram a necessidade, sobretudo no COA, de espaços seguros e acolhedores, com privacidade e profissionais capacitados e sensibilizados, com a participação da população LGBTQI+, além da reciclagem técnica dos profissionais de saúde, em particular os médicos, para se apropriarem das novas diretrizes relacionadas ao HIV. Ainda sobre a questão do cuidado, foi relatada a necessidade de os serviços de saúde fornecerem um acompanhamento psicológico para as PVHA, suprido pela figura do linkador, além da agilidade de consultas, exames e 
entrega dos resultados e forma de atendimento nas UBSs, principalmente para não desestimular a vinculação e a continuidade no tratamento.

\section{Aceitabilidade}

Para os profissionais do PAHA, a testagem rápida ofertada em distintas estratégias foi bem aceita, de forma geral, pelos HSH, porém com diferenças a depender do perfil e necessidades dos usuários. Para aqueles que acessaram o Consultório na Rua, houve resistência na testagem pelo fato de muitos não quererem ter conhecimento sobre o status sorológico diante da situação já bastante vulnerável em que viviam. Isso tornou-se um desafio para os profissionais, principalmente para entenderem e respeitarem a decisão de cada indivíduo em situação de rua sem esse interesse:

[...] primeiro em não querer saber sobre a sua sorologia, o que é um direito de cada um, então ele diz: ah eu não quero saber, minha vida já tá tão desgraçada que eu não quero ter notícias. Então, eu acho que isso é um primeiro momento assim, que a gente precisa respeitar apesar de tentar fazer todo um trabalho de sensibilização (ponto focal 4).

A demanda por testagem entre a população em situação de rua, mesmo entre aqueles que têm práticas homoeróticas, pode ser secundária diante das necessidades de saúde mais prementes para aqueles que estão na rua. Ela ocorrendo, no entanto, pode acabar sendo reprimida devido a barreiras de acesso ao cuidado que, muitas vezes, esta população encontra nos serviços de saúde por conta do estigma e discriminação a que está sujeita ou por dificuldades burocráticas, como a falta de documentação que os impede de acessar o serviço de saúde, que desafiam a universalidade do sistema. Para atender esta população de forma integral e integralizada aos demais atendimentos, a equipe do Consultório na Rua trabalhou com o conceito de "gestão de caso" e contou com um médico contratado especialmente para atender esses indivíduos.

O E-testing foi uma estratégia que surpreendeu em termos de kits de testes solicitados e entregues, mostrando-se uma tecnologia aceitável entre os HSH e efetiva para fazer a "ponte" entre os usuários e os serviços de saúde. Essa estratégia foi utilizada, sobretudo, pelos HSH que não queriam exposição para realizar a testagem e conseguiram privacidade e comodidade por meio do kit, como mencionado por um dos entrevistados:

[...] o desenho do projeto, pra mim, o mais importante foi o teste ir pra casa, pois as pessoas começaram a se testar mais apesar de suas particularidades, medos, vergonhas e afins (linkador, participante de grupo focal).

Porque eu acho que o maior problema também que a gente enfrenta é a vergonha de fazer o teste, então como eu, por exemplo, eu faço o que eu recebo por correio, então ele, você elimina essa barreira de você ter que conversar com as pessoas, você assumir que você precisa do teste (usuário do E-testing).

O PAHA, segundo os informantes-chave e usuários, contribuiu para uma maior visibilidade do trabalho realizado na ONG, tornando-a uma opção para o cuidado da saúde dos HSH e desmistificando a testagem na visão de alguns profissionais de saúde. Embora esta estratégia tenha sido apontada como acolhe- 
dora e gay-friendly, foi um espaço com pouca visibilidade dentro das estratégias de testagem para os usuários e houve preocupação com uma potencial quebra de sigilo "no meio LGBTQI+". Outro ponto destacado por alguns profissionais de saúde foi o fato de esta estratégia ser mais adequada para alcançar um público assumido com uma identidade LGBTQI+ e não aqueles com práticas homoeróticas, mas autodeclarados heterossexuais.

Eu acho que sim porque pelo menos aqui no Dignidade o que eu vejo é que eles se sentem mais à vontade de vir porque sabem que é uma equipe que tem pessoas, tem homens gays que estão fazendo testes, é um ambiente um pouco mais acolhedor (usuário da ONG).

A figura do linkador foi referida como fundamental na maior aceitação para testagem e tratamento, tanto na ONG quanto nas outras estratégias, servindo de escuta para muitos usuários sobre a descoberta da soropositividade e também tornando-se o apoio na difícil tarefa de revelar o diagnóstico para a família e amigos. O suporte técnico e emocional refletiu na demanda de alguns usuários sabidamente soropositivos à nova testagem apenas para poderem contar com o apoio do linkador do programa. Outro ponto mencionado foi o auxílio na navegação pelo sistema de saúde, pelo maior conhecimento que o linkador passa a ter sobre como a rede de saúde funciona, orientando melhor os usuários, e pelas orientações sobre HIV/Aids compartilhadas pelos linkadores.

[...] eu acho que o projeto dá possibilidades maravilhosas, como linkador, sabe? Tipo, se deu positivo já chega alguém com uma certa experiência sabendo do que está falando com uma abordagem mais tranquila e já te deixa mais confortável dentro dessa situação e já te apresenta, digamos assim, o leque de tratamentos e tudo o que a pessoa pode começar a fazer, e aí eu acho que a partir disso é da pessoa dizer o que que ela quer, se sim ou se não, e acho que esse, o apresentar o tratamento desse jeito, por exemplo, eu acho que o linkador é uma das coisas mais legais, porque o que falta, tem muita gente que não tem com quem conversar (usuário do E-testing).

A mobilidade e acessibilidade do trailer foram fatores que permitiram que um maior número de pessoas tivesse acesso ao serviço, mas, ao mesmo tempo, o fato de estar num local aberto e público pode ter contribuído para que pessoas não o utilizassem por preferirem maior privacidade e discrição, sendo apontado como uma estratégia em que as pessoas "não assumidas" poderiam não ir.

De maneira geral, as estratégias de testagem no PAHA foram bem aceitas. A proximidade dos serviços com a residência das pessoas, o grau de confiança no espaço em que era realizado o teste, o acesso a informações sobre o tempo de espera, o apoio, o anonimato, o sigilo e a privacidade foram pontos importantes, segundo os usuários, para a escolha do serviço da testagem. O Quadro 3 procurou, de forma sintética, apresentar os pontos positivos e negativos de cada estratégia do PAHA, a partir das entrevistas e observações, importantes para o desenvolvimento de melhorias no programa. 
Quadro 3 - Pontos positivos e negativos do PAHA em cada estratégia

\begin{tabular}{|c|c|c|}
\hline Estratégia & Pontos Positivos & Pontos negativos \\
\hline COA & $\begin{array}{l}\text { - Familiarização com o serviço } \\
\text { (referência municipal para testagem) } \\
\text { e equipe; } \\
\text { - Sigilo e privacidade; } \\
\text { - Maior suporte profissional; } \\
\text { - Maior credibilidade por ser unidade } \\
\text { de saúde; } \\
\text { - Oferece outros tipos de testagem; } \\
\text { - Acessa população de fora de Curitiba; } \\
\text { - Opção para quem não tem plano de } \\
\text { saúde. }\end{array}$ & $\begin{array}{l}\text { - Acessibilidade limitada } \\
\text { (horários mais restritos); } \\
\text { - Dispensação de medicamento } \\
\text { no mesmo local da testagem } \\
\text { (estigmatiza); } \\
\text { - Demora no atendimento; } \\
\text { - Embora haja preparo técnico da } \\
\text { equipe, houve relatos de estigma } \\
\text { e discriminação no atendimento } \\
\text { à população LGBTQI+. }\end{array}$ \\
\hline ONG & $\begin{array}{l}\text { - Serviço não discriminatório; } \\
\text { - Ter membros gays na equipe do } \\
\text { PAHA; } \\
\text { - Reconhecido pela comunidade } \\
\text { LGBTI; } \\
\text { - Oferece outros serviços, não apenas } \\
\text { testagem para HIV; } \\
\text { - Mais acolhedora para gays/ } \\
\text { homossexuais por ser mais direcionada } \\
\text { ao público LGBTQI+; } \\
\text { - Mais confortável; } \\
\text { - Segurança/confiança por "parecer } \\
\text { um laboratório"; } \\
\text { - Já tem experiência no atendimento à } \\
\text { população LGBTQI+. }\end{array}$ & $\begin{array}{l}\text { - Acessaria apenas "população } \\
\text { assumida"; } \\
\text { - Desconhecimento do serviço } \\
\text { de testagem oferecido na ONG; } \\
\text { - Potencial quebra de sigilo da } \\
\text { informação (resultado) no meio } \\
\text { LGBTQI+. }\end{array}$ \\
\hline Trailer & $\begin{array}{l}\text { - Oportunidade; } \\
\text { - Praticidade; } \\
\text { - Mobilidade; } \\
\text { - Localização estratégica (de passagem } \\
\text { das pessoas); } \\
\text { - Pessoas não são notadas em espaços } \\
\text { públicos de grande movimentação; } \\
\text { - Bom atendimento; } \\
\text { - Segurança/confiança por "parecer } \\
\text { um laboratório". }\end{array}$ & $\begin{array}{l}\text { - Espaço público - não acessa } \\
\text { HSH ("não assumidos"); } \\
\text { - Falta de discrição, chama } \\
\text { atenção. }\end{array}$ \\
\hline E-testing & $\begin{array}{l}\text { - Menos invasivo; } \\
\text { - Rapidez; } \\
\text { - Comodidade de se fazer em casa; } \\
\text { - Discrição ("permite não ter contato } \\
\text { pessoal"); } \\
\text { - Agilidade no resultado; } \\
\text { - Elimina a vergonha de se fazer o teste } \\
\text { em algum lugar (não exposição); } \\
\text { - Utiliza saliva e não sangue; } \\
\text { - Confere privacidade ou não } \\
\text { (dependendo com quem a pessoa } \\
\text { mora, se escolhida entrega domiciliar). }\end{array}$ & $\begin{array}{l}\text { - Necessidade de maior apoio } \\
\text { em caso de resultados reagentes } \\
\text { para HIV; } \\
\text { - Adequado para quem já tem } \\
\text { informação sobre HIV e só quer } \\
\text { fazer o teste, para maiores } \\
\text { informações requer outro serviço } \\
\text { (presencial-relacional). }\end{array}$ \\
\hline $\begin{array}{c}\text { Consultório } \\
\text { na Rua }\end{array}$ & $\begin{array}{l}\text { - Apoio de uma equipe sensibilizada } \\
\text { do projeto para essa estratégia } \\
\text { (contratação de um médico); } \\
\text { - Acesso a outros tipos de serviço de } \\
\text { saúde. }\end{array}$ & $\begin{array}{l}\text { - A falta de documentos dos } \\
\text { usuários pode barrar o acesso } \\
\text { deles aos serviços de saúde e } \\
\text { tratamento. }\end{array}$ \\
\hline
\end{tabular}

Fonte: Elaborado pelos autores, 2020. 


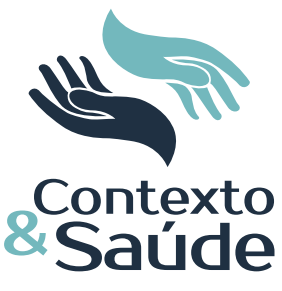

\section{DISCUSSÃO}

A avaliação da instalação do PAHA identificou que a aceitabilidade a novos modelos de atenção e a inovações em tecnologias diagnósticas e sociais é possível, como a vinculação por pares, é alta entre a população-chave, profissionais de saúde e gestores em saúde. Além disso, buscou-se uma assistência humanizada, não discriminatória e considerada eficiente para ampliar o acesso à testagem e aumentar a vinculação dos portadores de HIV à atenção em saúde.

A avaliação da prática da testagem em diferentes estratégias pode ser composta por distintos componentes, observando-se que no contexto do PAHA buscou-se também a melhoria de sua operacionalidade (ALVES; MAZON, 2016). $\mathrm{Na}$ avaliação de intervenções de saúde dessa natureza é importante que diversos atores sejam escutados para que, por meio de distintos pontos de vista sobre o mesmo objeto, se possa aprimorar o funcionamento do serviço, qualificar os profissionais, aperfeiçoar normas e rotinas e proporcionar dignidade aos sujeitos envolvidos (RIBEIRO; ROSA; FELACIO, 2015).

Todas as quatro categorias analisadas - cobertura, adequação, qualidade e aceitabilidade - trouxeram elementos importantes sobre as conquistas e as barreiras em torno da ampliação da testagem de HIV no PAHA. O sigilo, a confidencialidade, a segurança e a privacidade foram fundamentais na escolha da estratégia para a realização da testagem entre os HSH, assim como outros fatores. Por isso, aquelas que forneciam esses elementos foram as mais procuradas e tiveram maior aceitação. A proximidade com o local da testagem e o acesso à informação sobre o tempo de espera também foram elementos importantes na opção da estratégia, com esses fatores mostrando-se semelhantes em outras partes do mundo. Como exemplo, um estudo realizado em Manila, Filipinas, analisou o acesso dos HSH à testagem de HIV e revelou diversas causas conflitantes para a sua realização, como a localização distante dos Centros de Testagem, o tempo de espera muito longo, a abertura e o fechamento no horário de trabalho dos indivíduos e os locais não equitativos (WIJNGAARDEN et al., 2018).

No PAHA, algumas estratégias forneciam horários alternativos para a testagem, como a ONG e o trailer, ampliando, desta forma, o acesso. O E-testing, com a entrega (via correio e farmácia popular) de kits de autotestagem foi uma forma de os HSH manterem o sigilo, superando o receio de serem identificados no momento da testagem. Há evidências da efetividade da testagem rápida de HIV na captação de indivíduos que nunca se testaram, conforme indicado em uma pesquisa realizada na Espanha, na qual seis em cada dez pessoas que se testaram em unidade móvel, no período de 2008 a 2011, nunca haviam realizado um teste de HIV na vida; entre aqueles com resultado reagente estavam os HSH mais jovens (BELZA et al., 2015). A testagem rápida de HIV de fácil acesso tem se mostrado bem receptiva entre os jovens HSH, principalmente em estratégias que se distinguem dos serviços de testagem convencionais e conjugadas com o anonimato (LABHARDT et al., 2018).

Apesar de o COA ter sido a estratégia mais procurada pelos usuários do PAHA para testagem, algumas barreiras de acesso foram relatadas, como o fato de o prédio do COA ser reconhecido como um lugar de testagem e tratamento 


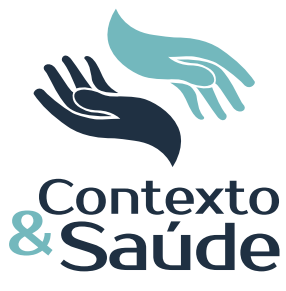

de HIV em Curitiba, podendo estigmatizar as pessoas que o procuram e houve a falta, identificada por alguns usuários, de um maior acolhimento em relação a questões singulares da população LGBTQI+ e às posturas moralistas em torno destas. Essas percepções indicaram que atitudes estigmatizantes a esta população em razão da orientação sexual e da vulnerabilidade à infeção pelo HIV ainda se faz presente no COA, constituindo-se em uma forte barreira na busca pela testagem, cuidado e atendimento, sobretudo na atenção básica, podendo interferir na vida dos HSH mediante as atitudes negativas e discriminatórias, trazendo uma série de consequências comportamentais (GARCIA; RAMOS, 2017).

O estigma e a discriminação relacionado ao HIV/Aids ainda podem ser conjugados com outros marcadores sociais, como orientação sexual, cor/raça, renda, moradia, nível educacional, entre outros, que se intersectam e exacerbam nos processos de discriminação que esta população pode enfrentar em serviços de saúde (UNAIDS, 2019). Essa questão veio à tona, em particular, nas categorias de avaliação do acesso adequação e qualidade. Para a superação dessa barreira seria necessária uma sensibilização das equipes e treinamentos, tanto na oferta da testagem do HIV quanto no cuidado para populações específicas (SHUBHA RAO et al., 2016). Esse ponto foi identificado no PAHA, principalmente a necessidade de sensibilização dos profissionais de saúde das UBSs e no acesso à testagem em algumas estratégias.

Apesar de o PAHA ter sido bem aceito pelos profissionais/gestores e usuários, que o viram como alternativa de testagem mais acolhedora e que incorpora preceitos de direitos humanos em seu atendimento, mostrando-se rápido e eficiente, essa perspectiva distingue-se quando comparada ao atendimento realizado nas UBSs no acesso aos exames, tratamento e na relação direta com os profissionais de saúde do serviço. No que diz respeito ao Consultório na Rua, a preocupação da população atendida estava na dificuldade em conseguir atendimento e tratamento por falta de documentação. Entre os fatores que podem prejudicar a realização da testagem de HIV na população em situação de rua está o medo de receber um diagnóstico positivo e o adoecimento (HINO; SANTOS; ROSA, 2018), como também a dificuldade de conseguir acesso aos serviços de saúde e por barreiras em virtude da sua condição, como a impossibilidade de comprovar moradia, uso de álcool, drogas e outras doenças.

Em relação às fragilidades da atenção em saúde aos HSH soropositivos, os conceitos de cuidado e vulnerabilidade podem ser utilizados nas práticas de saúde. Eles trariam uma renovação para as formas de "construção de diagnósticos de saúde" para os usuários do PAHA que acessam as UBSs, incorporando saberes para "além daqueles biomédicos e epidemiológicos" e trazendo os das ciências sociais, humanas e práticos". Para o diagnóstico ampliado, o cuidado deve ser construído a partir de práticas de saúde que possam considerar a autonomia dos indivíduos e incorporar seus saberes (CALAZANS; PINHEIRO; AYRES, 2018).

A figura dos linkadores, que acompanhavam os $\mathrm{HSH}$ com testes reagentes nos serviços de saúde até o início do tratamento, foi importante para criar a ligação entre a testagem e as UBSs, como também no acompanhamento de exames e apoio psicológico a partir de novos saberes incorporados. Além do contato pessoal, as trocas de mensagens (via WhatsApp) trouxeram esclarecimentos sobre

Editora Unijuí - Revista Contexto \& Saúde - ISSN 2176-7114 - v. 21, n. 43, jul./set. 2021 


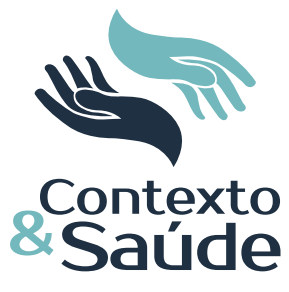

os próximos passos no processo de cuidado e tratamento e também em como abordar as questões pessoais reduzindo, assim, a vulnerabilidade dos usuários acompanhados. Essa noção parte do princípio de que a utilização de um conjunto de saberes, como o uso da tecnologia, torna-se fundamental para a transformação e o conhecimento das condições de saúde dos indivíduos (CALAZANS; PINHEIRO; AYRES, 2018).

Diversos projetos de testagem que utilizaram os linkadores como forma de aproximação e acompanhamento dos HSH com diagnóstico positivo foram bem aceitos por essa população e revelaram que esse método tem se mostrado eficiente na navegação após a testagem de HIV, ajudando a reduzir a ansiedade, esclarecendo dúvidas relacionadas ao tratamento, fornecendo mudanças no comportamento sexual e contribuindo para ampliar o acesso dos usuários aos serviços de saúde (BROWNRIGG et al., 2017).

As avaliações de implementação de um programa, conforme a que fora realizada, visam a promover seu desenvolvimento e melhoria, destacando-se que os avaliadores podem fornecer evidências que orientem os implementadores no desenvolvimento do programa e que possam ser utilizadas nas tomadas de decisão sobre a continuidade ou expansão (SPIEGELMAN, 2016).

Apesar de todo avanço do PAHA em relação à ampliação da testagem do HIV entre os HSH, como a vinculação dos casos positivos na atenção básica e seu acompanhamento até o início da TARV (linkagem), há ainda muito que se avançar na atenção a essa população. Destacam-se as situações de estigma, discriminação e violência homofóbica a que essa população está sujeita, tornando-a vulnerável tanto a situações de exposição ao risco de adquirir HIV, quanto, uma fez adquirido, a barreiras de acesso ao diagnóstico e ao cuidado integral. Por isso, torna-se fundamental investigar as possíveis barreiras de acesso à testagem e tratamento entre os HSH, como também entender as conexões entre as experiências sexuais e a vulnerabilidade ao HIV desses indivíduos (MORA; BRIGEIRO; MONTEIRO, 2018).

O atual desafio do PAHA é encontrar formas para a sua sustentabilidade, pois ele se mantém em Curitiba em nova fase centrada no tratamento imediato ao HIV, na assistência dos usuários e na prevenção ao vírus. Há alguns obstáculos nesse campo, como questões de cunho político (mudanças na gestão municipal e crise político-econômica nacional e local), custo para a manutenção dos equipamentos e equipes, necessidade de autotestes mais baratos e de fácil manuseio para uso amplo na rede de saúde municipal, entre outros, para que seja possível a continuidade das estratégias de testagem rápida de HIV introduzidas pelo projeto em Curitiba.

A despeito dos desafios ainda presentes para se encontrar mecanismos efetivos e eficientes de sustentabilidade das estratégias alternativas de aconseIhamento e testagem voluntária, o PAHA enfrentou desafios ao propor um novo modelo de atenção para a resposta nacional e local à epidemia concentrada do HIV entre a população HSH.

Editora Unijuí - Revista Contexto \& Saúde - ISSN 2176-7114 - v. 21, n. 43, jul./set. 2021 


\section{CONSIDERAÇÕES FINAIS}

O Projeto revelou como a aceitabilidade das inovações em tecnologias diagnósticas e de cuidado (vinculação por pares) é alta entre a população-chave, profissionais e gestores em saúde por ser, ao mesmo tempo, de alta resolutividade. A despeito das dificuldades no processo de implementação do PAHA, pode-se considerar que ele alcançou metas mais realísticas. Os profissionais envolvidos acumularam vasta experiência e lições aprendidas que ajudarão na continuidade do projeto e que poderão ser compartilhadas em sua adaptação a outros contextos e cidades.

Apesar da ampla avaliação qualitativa do PAHA na cidade de Curitiba, constatou-se limitações no estudo. Houve dificuldade na captação de usuários gays/ HSH para a composição do número almejado de grupos focais, a concentração de entrevistados gays (usuários e não usuários do PAHA) em um segmento de maior escolarização, Ensino Superior completo/incompleto e com melhor acesso aos serviços de saúde, além da dificuldade de atrair o público HSH sem identidade gay/bissexual. Ademais, a avaliação do PAHA foi realizada por aqueles que o colocaram em prática, ou seja, a partir de pessoas que estavam comprometidas com o seu êxito.

Com base no mapeamento dos pontos positivos e negativos da implementação do PAHA, os gestores e profissionais conseguiram ajustar os pontos negativos das estratégias para que o acesso à testagem rápida pudesse ter maior aceitação entre os HSH, ampliando o número de pessoas testadas, além de fortalecer aquelas estratégias mais bem aceitas por esse público.

Como possíveis desdobramentos, há previsão da instalação de um modelo semelhante de testagem em outras capitais do país, como Florianópolis e Campo Grande, já em curso; a ampliação e diversificação de estratégias e pontos de acesso à testagem de HIV para a diversidade do público HSH na Rede de Atenção Básica à Saúde, com inclusão de áreas periféricas da cidade de Curitiba, sobretudo em razão da saturação daquelas já existentes, bem como o compartilhamento das experiências do PAHA para que a ampliação do acesso à testagem de HIV em populações vulneráveis seja uma realidade no Brasil.

\section{AGRADECIMENTOS}

Aristides Barbosa Júnior, Greet Peersman, Raquel Miranda, Nena Lentini, Liza Rosso, David Harrad, Juliane Santos, Adriane Wollmann, Elina Sakurada, Roberto de Jesus, Cristiane Nakamura, Raquel Torres, Raquel de Boni, Leonardo Lincoln, Bernardo Almeida, Carolina Ribeiro, Milena Costa, Paola Carriel, e a todos os linkadores e educadores de pares.

\section{FINANCIAMENTO}

O projeto A Hora é Agora foi financiado por meio do Acordo de Cooperação entre a Ensp/Fiocruz-Fiotec e os Centros de Controle e Prevenção de Doenças dos Estados Unidos da América - CDC, com recursos do Plano de Emergência

Editora Unijuí - Revista Contexto \& Saúde - ISSN 2176-7114 - v. 21, n. 43, jul./set. 2021 
do presidente dos EUA para Alívio da Aids - Pepfar. Seu conteúdo é responsabilidade apenas dos autores e não representa necessariamente a visão oficial do financiador.

\section{REFERÊNCIAS}

ALVES, G. C.; MAZON, L. M. Avaliação da implantação dos testes rápidos para diagnóstico do HIV/AIDS e hepatites virais em municípios do planalto norte catarinense. Enfermagem Revista, Belo Horizonte, v. 19, n. 2, p. 152-168, 2016.

BRASIL. Ministério da Saúde. Secretaria de Vigilância em Saúde. Departamento de DST, Aids e Hepatites Virais. Pesquisa de conhecimento, atitudes e práticas na população brasileira (2013). Brasília: Ministério da Saúde, 2016.

BRASIL. Boletim Epidemiológico de HIV e Aids 2019. Ministério da Saúde. Secretaria de Vigilância em Saúde. Departamento de Doenças de Condições Crônicas e Infecções. Número Especial. Brasília, 2019. Disponível em: http://www.aids.gov.br/pt-br/pub/2019/ boletim-epidemiologico-de-hivaids-2019. Acesso em: 9 dez. 2019.

BELZA, M. J. et al. Assessment of an outreach street-based HIV rapid testing programme as a strategy to promote early diagnosis: a comparison with two surveillance systems in spain, 2008-2011. Eurosurveillance, Stockholm, v. 20, n. 14, p. 1-11, 2015.

BROWNRIGG, B. et al. Improving linkage to HIV care at low-threshold STI/HIV testing sites: An evaluation of the Immediate Staging Pilot Project in Vancouver, British Columbia. Canadian Journal of Public Health, Ottawa, v. 108, n. 1, p. e79-e84, 2017.

CALAZANS, G. J.; PINHEIRO, T. F.; AYRES, J. R. C. M. Vulnerabilidade programática e cuidado público: panorama das políticas de prevenção do HIV e da Aids voltadas para gays e outros HSH no Brasil. Sexualidad, Salud y Sociedad-Revista Latinoamericana, Rio de Janeiro, n. 29, p. 263-293, 2018.

DE BONI, R. B. et al. Self-testing, communication and information technology to promote HIV diagnosis among young gay and other men who have sex with men (MSM) in Brazil. Journal of the International AIDS Society, v. 21, n. S5, p. 106-108, 2018.

EMMERICK, I. C. M. et al. Barriers in household access to medicines for chronic conditions in three Latin American countries. International Journal for Equity in Health, n. 14, v. 115, p. 1-14, 2015.

GARCIA, R.; RAMOS, D. G. Experiência de homens que fazem sexo com homens vivendo com HIV: diferentes processos emocionais. Revista Cuidarte Enfermagem, v. 11, n. 1, p. 93-99, 2017.

GRECO, D. B. Trinta anos de enfrentamento à epidemia da Aids no Brasil, 1985-2015. Ciênc. Saúde Coletiva, Rio de Janeiro, v. 21, n. 5, p. 1.553-1.564, 2016.

HINO, P.; SANTOS, J. O.; ROSA, A. S. Pessoas que vivenciam situação de rua sob o olhar da saúde. Rev. Bras. Enferm., v. 71(supl1), p. 32-40, 2018.

KERR, L. et al. HIV prevalence among men who have sex with men in Brazil: results of the 2nd national survey using respondent-driven sampling. Medicine, Baltimore, v. 97, n. 1 (Suppl 1), p. S9-S15, 2018.

KNAUTH, D. R.; LEAL, A. F. A expansão das Ciências Sociais na Saúde Coletiva: usos e abusos da pesquisa qualitativa. Interface: Comunicação, Saúde, Educação, Botucatu, v. 18, n. 50, p. 457-467, 2014.

LABHARDT, N. D. et al. Effect of Offering Same-Day ART vs Usual Health Facility Referral During Home-Based HIV Testing on Linkage to Care and Viral Suppression Among Adults With HIV in Lesotho. The CASCADE Randomized Clinical Trial. Jama, v. 319, n. 11, p. 1.103-1.112, 2018.

MAEDA, K. et al. Discovery and Development of Anti-HIV Therapeutic Agents: Progress Towards Improved HIV Medication. Current Topics in Medicinal Chemistry, v. 19, n. 18, p. 1.621-1.649, 2019.

Editora Unijuí - Revista Contexto \& Saúde - ISSN 2176-7114 - v. 21, n. 43, jul./set. 2021 
MATIN, B. K et al. The predictors of access to health services for people with disabilities: A cross sectional study in Iranian context. Med. J Islam Repub. Iran, Tehran, v. 33, n. 125, p. 1-7, 2019.

MINAYO, M. C. de S. Importância da avaliação qualitativa combinada com outras modalidades de avaliação. Sau. \& Transf. Soc., Florianópolis, v. 1, n. 3, p. 2-11, 2011.

MONTEIRO, S. S. et al. Desafios do tratamento como prevenção do HIV no Brasil: uma análise a partir da literatura sobre testagem. Ciência \& Saúde Coletiva, Rio de Janeiro, v. 24, n. 5, p. 1.793-1.807, 2019.

MORA, C. M.; BRIGEIRO, M.; MONTEIRO, S. A testagem do HIV entre "HSH": tecnologias de prevenção, moralidade sexual e autovigilância sorológica. Physis: Revista de Saúde Coletiva, Rio de Janeiro, v. 28, n. 2, p. 1-28, 2018.

PATTON, M. Q. Qualitative Research \& Evaluation Methods: Integrating Theory and Practice. 4. ed. London: Sage, 2015.

PROCTOR, E. et al. Outcomes for implementation research: conceptual distinctions, measurement challenges, and research agenda. Adm. Policy Ment Health, n. 38, p. 65-76, 2011.

PENCHANSKY, D. B. A.; THOMAS, J. W. The Concept of Access: Definition and Relationship to Consumer Satisfaction. Medical Care, v. 19, n. 2, p. 127-40, 1981.

RIBEIRO, I. M.; ROSA, A. F.; FELACIO, V. C. M. Avaliação dos serviços de assistência em HIV/aids na perspectiva de portadores. Revista Interdisciplinar, Teresina, v. 8, n. 4, p. 7181, 2015.

SALCI, M. A.; SILVA, D. M. G. V.; MEIRELLES, B. H. S. Avaliação no sistema de saúde brasileiro. Cienc. Cuid. Saúde, v. 17, n. 2, p. 1-6, 2018.

SHACHAM, E. et al. Enhancing Adherence to Care in the HIV Care Continuum: The Barrier Elimination and Care Navigation (BEACON) Project Evaluation. Aids Behav, v. 22, p. 258264, 2018.

SHUBHA, R. A. O. M. P. H. et al. HIV Testing and Outcomes Among Hispanics/Latinos United States, Puerto Rico, and U.S. Virgin Islands, 2014. Morbidity and Mortality Weekly Report, Atlanta, v. 65, n. 40, p. 1.099-1.103, 2016.

SPIEGELMAN, D. Evaluating Public Health Interventions: 1. Examples, Definitions, and a Personal Note. American Journal of Public Health, v. 106, n. 1, p. 70-73, 2016.

UNAIDS. Índice de Estigma em Relação às Pessoas Vivendo com HIV/Aids - Brasil. dez. 2019. Disponível em: https://unaids.org.br/wp-content/uploads/2019/12/2019_12_06_ Exec_sum_Stigma_Index-2.pdf

VIACAVA, F. et al. Avaliação de desempenho de sistemas de saúde: um modelo de análise. Ciênc. Saúde Coletiva, Rio de Janeiro, v. 17, n. 4, p. 921-934, 2012.

WIJNGAARDEN, J. W. de L. V. et al. "I am not promiscuous enough!": Exploring the low uptake of HIV testing by gay men and other men who have sex with men in Metro Manila, Philippines. PLoS ONE, San Francisco, v. 13, n.7, p. 1-12, 2018. 